\title{
Violência contra a Mulher, Casas-Abrigo e Redes Sociais: Revisão Sistemática da Literatura
}

\author{
Scheila Krenkel \\ Universidade Federal de Santa Catarina, \\ Florianópolis, SC, Brasil.
}

\author{
Carmen Leontina Ojeda Ocampo Moré \\ Universidade Federal de Santa Catarina \\ Florianópolis, SC, Brasil.
}

\begin{abstract}
Resumo: Este estudo teve como objetivo caracterizar a produção científica de artigos empíricos sobre casas-abrigo e redes sociais no contexto da violência contra a mulher. Buscaramse artigos publicados entre 2004 e 2015, no Portal de Periódicos da Capes. Os descritores utilizados foram "shelter" e "social networks", combinados com "violence against women" e suas variações: "domestic violence"/"gender violence". De 1.536 estudos encontrados, 33 atenderam aos critérios de inclusão estabelecidos e foram organizados em duas categorias temáticas. Os resultados mostraram aspectos positivos da passagem das mulheres pela casa-abrigo, como o apoio oferecido pelos profissionais, além de aspectos dificultadores após a saída do local, principalmente em relação à geração de trabalho e renda. As redes sociais foram apontadas como um importante recurso no enfrentamento da violência, sobretudo pelo apoio da família de origem e das relações de amizade. Com base nos resultados e limitações apontados nos estudos, sugere-se o desenvolvimento de novas pesquisas que problematizem a interrelação das práticas profissionais realizadas em casas-abrigo e o acompanhamento das mulheres após saírem do local, assim como, aprofundar a análise dos vínculos afetivos que sustentam as funções desempenhadas pelos membros que constituem as redes sociais configuradas.
\end{abstract}

Palavras-chave: Violência contra a Mulher, Redes Sociais, Revisão de Literatura, Abrigo.

\section{Violence against Women, Shelters and Social Networks: Systematic Review of the Literature}

\begin{abstract}
This study aimed to characterize the scientific production of empirical articles about shelters and social networks in the context of violence against women. The research included articles published between 2004 and 2015, at the CAPES Periodic Portal. The descriptors used were "shelter" and "social networks", along with "violence against women" and its variations: "domestic violence"/ "gender violence". Of 1536 studiesfound, 33 attended to the inclusion criteria established and were organized in two thematic categories. The results showed positive aspects of the women's permanence at the shelters like the support provided by their professionals, as well as the negative aspects which made their lives difficult after they left the shelters, such as finding a job and having an income. Social networks were pointed as an important resource in coping with violence, especially through the original family support and friendship. Based on the results and limitations pointed in the studies, it is suggested the development of new researches that explore the professional practice interrelation in women's shelter and the accompaniment of women after leaving the shelter, as well as studies that deepen the analysis of the emotional bonds that sustain functions performed by members that compose the social networks.
\end{abstract}

Keywords: Violence Against Women, Social Networks, Literature Review, Shelter. 


\title{
Violencia contra la Mujer, Casas de Acogida y Redes Sociales: Revisión Sistemática de la Literatura
}

\begin{abstract}
Resumen: El objetivo de este estudio fue caracterizar la producción científica de los artículos empíricos sobre casas de acogida y redes sociales en el contexto de la violencia contra la mujer. Sebuscaron artículos publicados entre2004y2015, en elPortal de PeriódicosCAPES. Los descriptores utilizados fueron "shelter" y "social networks" combinados con "violence against women" y sus variaciones: "domestic violence" / "gender violence". De 1536 artículos, 33 correspondieron a los criterios de inclusión, siendo organizados en dos categorías temáticas. Los resultados evidenciaron aspectos positivos de la estadía en la casa de acogida, como el apoyo ofrecido por los profesionales, y aspectos negativos después de la salida de la Casa, como la falta de empleo y/o rendimientos. Las redes sociales, familia y amistades fueron identificadas como importantes recursos de enfrentamiento de la violencia. De acuerdo con los resultados y las limitaciones de las investigaciones, se sugiere hacer nuevos estudios que problematicen la interrelación de las prácticas profesionales realizadas en las casas de acogida y el seguimiento de las mujeres después de salir del local, así como profundizar el análisis de los vínculos afectivos que sustentan las funciones desarrolladas por los miembros que constituyen las redes sociales configuradas.
\end{abstract}

Palabras clave:Violencia contra la Mujer, Redes Sociales, Revisión de la Literatura, Casa de Acogida.

\section{Introdução}

A violência contra a mulher é compreendida como qualquer ato violento que inclua ameaças, coerções, privação da liberdade baseada no gênero e que resulte ou possa resultar em danos nas esferas física, sexual e/ou emocional (United Nations ONU, 1993). De acordo com a Organização Mundial da Saúde (World Health Organization - WHO, 2014), vivenciar uma situação de violência prejudica o desenvolvimento vital das mulheres, podendo acarretar problemas graves para a saúde física, mental, sexual e reprodutiva, a curto e longo prazo, gerando altos custos econômicos e sociais. A violência contra a mulher, sobretudo a violência por parceiro íntimo e a violência sexual, está entre os principais problemas de saúde pública e violação dos direitos humanos. Os índices mundiais mostram que $30 \%$ das mulheres admitem já ter sofrido violência física ou sexual por seu parceiro, ao longo da vida, e $38 \%$ dos assassinatos contra mulheres são cometidos por seu parceiro ou ex-parceiro íntimo (WHO, 2014).

Na década de 1970, os movimentos feministas presentes em diversas partes do mundo foram os responsáveis pelo surgimento dos primeiros abrigos para mulheres que viviam em situação de violência, como forma de enfrentamento do problema. O ativismo, as denúncias e as reivindicações dos movimentos femi- nistas e das mulheres contribuíram para a visibilização das questões de gênero e apontaram para a falta de políticas públicas, programas e serviços que pudessem auxiliar as mulheres na garantia dos seus direitos. A primeira casa-abrigo de que se tem registro foi criada em 1971, na cidade de Chiswick, em Londres, na Inglaterra. De início, era um local criado para o encontro de mulheres que buscavam ajuda para seus problemas cotidianos; tornou-se um abrigo diante da necessidade de acolhimento e segurança demandados pelas mulheres que frequentavam aquele espaço e que vivenciavam situações de violência contra si e seus filhos, em suas casas (Rocha, 2007).

As casas-abrigos são locais de caráter temporário, seguros e sigilosos que têm por objetivo garantir a integridade física e psicológica das mulheres que estão em situação de violência e sob risco iminente de morte. As ações realizadas nas casas-abrigo estão pautadas em: promover o atendimento integral e interdisciplinar às mulheres e a seus filhos, especialmente nas áreas social, jurídica e psicológica; promover condições para a reinserção social da mulher após sua saída da casa-abrigo, como trabalho e renda, moradia, creche para os filhos e inserção nos programas de saúde; informar à mulher quanto aos seus direitos e meios para exercê-los; oferecer um ambiente acolhedor para as mulheres visando ao exercício de sua autonomia e recuperação da auto- 
estima, atuando como um importante dispositivo no conjunto de recursos para o enfrentamento da violência contra a mulher (Brasil, 2011).

$\mathrm{O}$ acesso das mulheres a casa-abrigo pode ocorrer por meio dos serviços de assistência social aos quais as casas-abrigo são vinculadas ou pela denúncia da violência, em que a delegacia realiza o encaminhamento aos órgãos competentes ou diretamente para a casa-abrigo. $\mathrm{O}$ tempo de permanência das mulheres no local varia de acordo com cada caso, considerando o estado psicológico e as condições de segurança necessárias para retomar suas vidas socialmente. A equipe de profissionais que realiza intervenção nas casas-abrigos pertence às áreas da saúde, jurídica, psicológica, assistencial e administrativa (Brasil, 2011).

Além do acolhimento oferecido nas casas-abrigo, para o enfrentamento da situação de violência, as mulheres também procuram pelas pessoas da sua rede social. Tendo em vista a literatura sobre a temática das "redes", cabe esclarecer que as produções bibliográficas apresentam variedade de definições que aludem, também, aos termos "suporte social", "redes informais", "redes sociais" e "apoio social". O suporte social (ou redes formais) refere-se ao conjunto de instituições e organizações formais que dirigem suas práticas para ações de prevenção e promoção da saúde, de modo a minimizar o estresse e aumentar o bem estar das pessoas (Ornelas, 2008). São exemplos de organizações/instituições que prestam suporte social: hospitais, postos de saúde, delegacias, centros de referência e casas-abrigo.

Por outro lado, há autores que utilizam redes informais ao se referirem às pessoas que compõem a família nuclear/extensa e demais pessoas da comunidade que estabelecem uma relação afetiva próxima (Rosa, Benício, Alves, \& Lebrão, 2007). Para Gonçalves, Pawlowski, Bandeira e Piccinini (2011), o termo redes sociais, refere-se à ideia de pessoas interconectadas em uma rede de relações tanto formais quanto informais, voltando-se mais para aspectos relacionados à estrutura da rede, como tamanho, composição, densidade e reciprocidade. Os mesmos autores definem o apoio social como uma das funções desempenhadas pelos membros da rede social de um indivíduo. Cabe mencionar que, com relação às definições que se referem às "redes sociais", no desenvolvimento deste artigo foram respeitadas aquelas empregadas pelos autores em seus estudos, conforme a abordagem teórica por eles utilizada.

Para Sluzki (2003), as redes sociais que são aquelas formadas por todas as relações consideradas sig- nificativas, diferenciadas das demais e que são capazes de oferecer ajuda e apoio em momentos de crise. Fazem parte das redes sociais a família, os amigos, os colegas de trabalho ou estudo, e a comunidade, incluindo vizinhos, pessoas da crença religiosa, profissionais de saúde e assistenciais (Sluzki, 2003).

A qualidade das relações pode ser compreendida por meio das funções desempenhadas pelas pessoas das redes sociais. Estas funções são: a) companhia social, que diz respeito à realização de atividades conjuntas ou, simplesmente, a estar juntos; b) apoio emocional, caracterizado tanto pelos intercâmbios com atitude emocional positiva como pelo clima de compreensão e empatia; c) guia cognitivo e de conselho, consiste na oferta de informações pessoais, sociais e modelos de referência; d) a regulação social reafirma as responsabilidades e os papéis das pessoas, além de favorecer a resolução de conflitos; e) ajuda material ou de serviços, caracterizada pela contribuição financeira ou por meio de indicações a serviços com especialistas; f) acesso a novos contatos, que diz respeito à abertura de portas para novas conexões com pessoas e redes que até então não faziam parte da rede do indivíduo/família (Sluzki, 2003).

Conforme aponta Sluzki (2003), em nível existencial, as relações humanas contribuem para dar sentido à vida das pessoas, favorecem a organização da identidade, uma vez que as pessoas agem por intermédio do olhar e das ações dos outros. Segundo o referido autor, a rede social de um indivíduo é uma das chaves centrais para o seu bem-estar, pois influencia no cuidado com a saúde, favorece comportamentos corretivos e práticas de cuidado, sendo, por isso, associada positivamente com a sobrevida.

Diante do exposto, o objetivo do presente estudo foi caracterizar a produção científica de artigos empíricos sobre casas-abrigo e redes sociais no contexto da violência contra a mulher. Considera-se que a relevância do presente trabalho se assenta na possibilidade de visibilizar as redes sociais configuradas em torno da mulher em situação de violência e, principalmente, subsidiar reflexões sobre a influência das casas-abrigo no processo de acolhimento dessas mulheres. Da mesma forma, espera-se contribuir com o aprimoramento das intervenções desenvolvidas por profissionais que atendem a esta demanda específica e evidenciar as lacunas do campo da produção científica, com vista a subsidiar novas pesquisas nas temáticas de estudo do presente trabalho. 


\section{Método}

Esse estudo se caracteriza como revisão sistemática de literatura, a qual permite identificar e buscar informações disponíveis sobre um tema específico. Uma revisão de literatura contribuiu para que se consiga extrair os principais aportes e limitações dos estudos para o campo do conhecimento, constituindo-se como uma tarefa útil e imprescindível para a pesquisa e prática profissional (Ossó, 2014). A pesquisa bibliográfica sobre casas-abrigo e redes sociais no contexto da violência contra a mulher ocorreu entre julho de 2015 e janeiro de 2016, por meio do acesso ao Portal de Periódicos da Capes (Coordenação de Aperfeiçoamento de Pessoal de Nível Superior). O referido Portal contempla em seu acervo 37 mil títulos com texto completo, reunidos em 126 bases de dados de diferentes áreas de conhecimento.

No intuito de acessar o maior número de artigos, foi utilizado o Serviço VPN (Virtual Private Network) da Universidade à qual pertencem as autoras desse manuscrito. O Portal da Capes oferece um conjunto de possibilidades de refinamento de busca. Dessa maneira, foi utilizada a ferramenta "busca avançada", inseridos os descritores e assinalada a opção "qualquer", que significa que estes poderiam aparecer no título, como autor ou no assunto do documento. O tempo referiu-se aos últimos 10 anos, conforme opção do Portal, incluindo as datas referentes ao período de janeiro de 2004 e dezembro 2015, para que se pudesse ter acesso aos estudos publicados ainda mais recentes. O tipo de material selecionado foi "artigo", com texto completo disponível, revisado por pares e escrito no idioma inglês, considerando as opções: inglês, francês ou alemão. Para inclusão na presente pesquisa, os estudos deveriam atender aos seguintes critérios: a) serem artigos empíricos, b) terem seu texto completo e disponível online, c) estarem escritos em português, inglês ou espanhol, d) terem sido publicados entre janeiro de 2004 e dezembro de 2015, e) a violência contra a mulher ter sido praticada pelo parceiro íntimo.

De modo a contemplar os temas centrais propostos nesse estudo foram realizadas três revisões de literatura. A primeira teve por objetivo encontrar artigos empíricos que abordassem a experiência de profissionais vinculados a casas-abrigo e/ou de mulheres que estavam ou estiveram no local, objetivo este guiado pela seguinte pergunta: Quais as experiências de profissionais vinculados a casas-abrigo e/ou de mulheres que vivenciaram situação de violência durante ou após a passagem pelo local? Para responder a esta pergunta, no Portal da Capes foram utilizados os descritores: "violence against women", "gender violence" $\mathrm{e}$ "domestic violence", todos associados à palavra "shelter", por meio do operador lógico AND. Optou-se por utilizar estes descritores tendo em vista as diferentes perspectivas teóricas que norteiam os estudos sobre violência contra a mulher e também com a intenção de localizar maior número de artigos. Foram encontrados 591 documentos, dos quais 14 atendiam aos critérios de inclusão para este estudo.

A segunda revisão de literatura teve por objetivo encontrar artigos empíricos, cujas redes sociais e de suporte social tivessem sido procuradas por mulheres em situação de violência à procura de ajuda para o enfrentamento do problema. A busca por artigos nesse momento foi orientada pela pergunta: Qual a influência das redes sociais e de suporte social no enfrentamento da violência contra a mulher? Para responder a esta pergunta também foram consideradas as variações dos termos relacionados aos temas e utilizadas as seguintes combinações de descritores e operadores lógicos: social networks OR social support AND violence against women, domestic violence e gender violence. Os documentos encontrados totalizaram 890, dos quais 19 passaram a fazer parte do conjunto de artigos a serem analisados neste estudo.

A terceira revisão de literatura foi realizada com o objetivo de encontrar artigos empíricos que apresentassem relação entre os temas violência contra a mulher, casa-abrigo e redes sociais. Do total de 55 artigos encontrados, 12 foram lidos na íntegra, mas nenhum foi incluído neste estudo, pois apresentavam uma discussão superficial ou não específica em torno dos três temas.

A análise dos dados teve como referência a análise de conteúdo temática (Olabuénaga, 2009), a qual se sustenta em realizar uma leitura crítica e aprofundada do material encontrado, visando à melhor descrição e interpretação dos dados da pesquisa. Diante disso, a análise qualitativa da identificação e organização das informações coletadas seguiu duas etapas: 1) Num primeiro momento, foram lidos os títulos e/ou os resumos de todos os documentos encontrados. Quando o resumo não era suficientemente claro para decidir a inclusão dos estudos, o documento era lido parcialmente (método e resultados) ou na íntegra. Em caso de dúvida sobre a inclusão do artigo, pediu-se para outro pesquisador com experiência na área realizar a leitura na íntegra. 2) Realizada a seleção dos artigos que aten- 
diam aos critérios de inclusão e respondiam as perguntas norteadoras desta revisão de literatura, todos foram criteriosamente lidos na íntegra. Os dados bibliométricos e sistemáticos posteriormente foram analisados e serão apresentados em continuação.

\section{Resultados e Discussão}

Fundamentados no procedimento metodológico de revisão de literatura, os estudos que compõem o corpus de análise do presente trabalho referem-se aos 14 artigos encontrados na primeira revisão e aos outros 19 artigos encontrados no segundo procedimento de revisão, totalizando 33 artigos. Cada conjunto de artigos foi organizado em duas categorias temáticas, nomeadas com base nos descritores utilizados na busca pela produção científica sobre o tema. A análise dos resultados dos estudos contemplou a identificação de ideias principais ou núcleos de sentido correspondentes a cada categoria temática, conforme pode ser visualizado na Tabela.

\section{Violência contra a mulher e Casas-abrigo}

Nesta categoria, estão reunidos os dados bibliométricos e os principais resultados de 14 estudos. No que se refere aos dados bibliométricos dos artigos, o ano de 2005 foi o que teve maior número de produções (três artigos), seguido por 2008, 2013 e 2015 com dois artigos cada, e 2007, 2010, 2011, 2012 e 2014 com um estudo publicado em cada ano. Essa informação revela que o maior número de publicações ocorreu há mais de 10 anos e nos últimos anos foi publicado apenas um artigo anual, evidenciando uma produção científica ainda escassa sobre o tema.

Quanto à natureza das pesquisas, houve equilíbrio entre estudos qualitativos e quantitativos, com sete cada, o que mostra que a produção de conhecimento sobre a temática em questão está sendo desenvolvida sob diferentes perspectivas teórico-metodológicas. No que se refere aos instrumentos e técnicas de coleta de dados foram utilizados: mapas conceituais, entrevistas semiestruturadas, observação participante, grupos focais, questionários, escalas e inventários. Sete estudos utilizaram mais de um instrumento/técnica de coleta de dados, destacando o uso da entrevista semiestruturada em oito dos 14 estudos. Com relação aos participantes das pesquisas, 10 delas foram constituídas somente por mulheres em situação de violência, três por profissionais vinculados a casas-abrigo e uma da qual participaram tanto as mulheres quanto profissionais. Sobre os locais em que foram realizados os 14 estudos - o que permite uma leitura em termos contextuais -, observaram-se países localizados nos diferentes continentes: Estados Unidos ( $(n=5)$, Paquistão $(n=2)$, Canadá $(\mathrm{n}=1)$, Holanda $(\mathrm{n}=1)$, Turquia $(\mathrm{n}=1)$, Portugal $(\mathrm{n}=1)$, Noruega $(\mathrm{n}=1)$, Israel $(\mathrm{n}=1)$ e África do Sul $(\mathrm{n}=1)$. A esse respeito, destaca-se a maior produção de artigos empíricos nos Estados Unidos e a inexistência de estudos no cenário brasileiro, o que evidencia uma lacuna na produção de conhecimento sobre a temática no contexto nacional.

Em relação aos principais resultados dos estudos, no que tange à entrada na casa-abrigo (1.1), as mulheres paquistanesas, participantes da pesquisa de Critelli (2012), foram para o abrigo por sofrerem violência física grave e terem como consequência ossos, dentes e costelas quebradas, ferimentos na cabeça e nos olhos, além de terem sofrido violência psicológica e financeira. Diante dessa situação, a busca por ajuda e a ida para a casa-abrigo também esteve relacionada ao medo de morrer e ao medo de perder ou se afastar

Tabela

Categorias temáticas e núcleos de sentido analisados

\begin{tabular}{ll}
\hline Categorias temáticas & \multicolumn{1}{c}{ Núcleos de sentido } \\
\hline 1.Violência contra a mulher e casas-abrigo & 1.1 Entrada na casa-abrigo \\
& 1.2 Repercussões da passagem pela casa-abrigo \\
& 1.3 Saída da casa-abrigo \\
2.Violência contra a mulher e redes sociais & 2.1 Pessoas da rede social \\
& 2.2 Funções desempenhadas pelas redes \\
& 2.3 Isolamento social \\
& 2.4 Rede de suporte social \\
\hline
\end{tabular}


dos filhos. As participantes do referido estudo mencionaram ter dificuldades em falar sobre seus problemas com as pessoas da sua rede de relações, pois os sentimentos eram minimizados e as pessoas aconselhavam a manter o casamento em nome da honra da família. Esse aspecto teve relação com a dificuldade ao acesso às casas-abrigo seja por permanecerem mais tempo com os parceiros, seja pela falta de acesso às informações que levassem as mulheres até esses locais de proteção (Critelli, 2012).

Nessa perspectiva, um estudo comparativo (Galano, Hunter, Howell, Miller, \& Graham-Bermann, 2013) revelou que mulheres que foram para o abrigo sofreram maior número de episódios de violência física e psicológica quando comparadas com as que não utilizaram o serviço. Essas mulheres também apresentavam mais sintomas depressivos e presença de traumas do que as do grupo de controle.

Quanto às repercussões da passagem pela casa-abrigo (1.2), para muitas mulheres $(n=18)$, da pesquisa de Critelli (2012) o abrigo foi a primeira oportunidade que tiveram de falar abertamente sobre suas experiências de violência, com outras mulheres que viveram situações semelhantes. As participantes relataram ter encontrado no abrigo suporte social, aceitação e aconselhamento da equipe, fato este que contribuiu para a construção da autoconfiança e o empoderamento, favorecidos pelas oportunidades de emprego e formação profissional (Critelli, 2012).

Nessa direção, nos estudos de Wright, Kiguwa e Potter (2007) e Tutty (2015), as mulheres abrigadas mencionaram ter recebido, durante sua passagem pela casa-abrigo, apoio emocional e conselhos, informações obtidas sobre como lidar com o estresse e a raiva, além de como melhorar a autoestima e sentirem-se em uma local seguro. Os resultados das referidas pesquisas indicaram que o abrigo adotou uma mistura de abordagens terapêuticas, que envolve não apenas a consideração do problema em nível social, mas também abrange questões em nível individual, o que contribuiu para que a experiência de abrigamento fosse considerada como positiva pelas participantes (Tutty, 2015; Wright, Kiguwa, \& Potter, 2007).

No estudo de Few (2005), as participantes mencionaram que as outras mulheres abrigadas e os profissionais da casa-abrigo se tornaram uma nova família naquele momento estressante. Também disseram sentirem-se apoiadas e satisfeitas com o trabalho realizado no serviço (Few, 2005). Da mesma maneira, a pesquisa de Magalhães, Morais e Castro (2011) mostrou que entre as funções da equipe destacam-se as de apoiar, conversar e auxiliar as mulheres e as crianças abrigadas quanto às suas necessidades emocionais. Os profissionais mencionaram que trabalhar na área da violência exige grande disponibilidade e que é difícil se desligarem do trabalho quando regressam a suas casas. Com relação à prática, os profissionais relataram a limitação de trabalhar com as dificuldades psicológicas das mulheres decorrentes da situação de violência, a morosidade dos procedimentos judiciais e a dificuldade de encontrar habitação e emprego para as mulheres ao saírem da casa-abrigo (Magalhães et al., 2011).

A pesquisa de Constantino, Kim e Crane (2005) utilizou um grupo de intervenção e um grupo controle para testar a viabilidade e a eficácia da intervenção de apoio social de um abrigo para mulheres em situação de violência doméstica. O grupo de intervenção teve maior progresso nos sintomas relacionados aos distúrbios psicológicos e na percepção da disponibilidade de apoio social do que o grupo controle. Isso sugere, segundo as autoras, que o grupo de intervenção estruturado desde a entrada das mulheres no abrigo pode ser considerado eficaz na redução de sintomas psicológicos relacionados ao estresse.

O fortalecimento das mulheres foi apontado como objetivo e princípio orientador da casa-abrigo, segundo os fundadores e funcionários do local que participaram da pesquisa de Critelli e Wilett (2010), no Paquistão. A maior dificuldade encontrada pelos participantes refere-se à reinserção social das mulheres, ou seja, principalmente em auxiliá-las a ter habitação e emprego ao saírem da casa-abrigo. Já para a maioria das mulheres $(n=8 / 11)$ participantes da pesquisa de Glenn e Goodman (2015), a rigidez das regras da casa-abrigo era fator de frustração, mágoa ou raiva e dificultava sua permanência no local. Todas as participantes reconheciam a necessidade de regras no abrigo, mas todas sugeriram que estas fossem mais flexíveis.

Na Turquia, conforme a pesquisa de Diner e Toktas (2013), o principal motivo que inibe a construção de mais abrigos para mulheres em situação de violência é o investimento financeiro destinado a este fim, tendo em vista que não parece ser uma prioridade no país. Outra razão para novas construções e a manutenção de abrigos já existentes é a dificuldade de manter a segurança das mulheres, uma vez que, nesse contexto cultural, ao sair de casa, a mulher fere 
a "honra" do homem e da família e seu marido tentará encontrá-la para mantê-la sob seu olhar e controle. Assim, na Turquia, as casas-abrigo ainda são vistas como locais que estão em desenvolvimento, sobretudo no que concerne à segurança das mulheres (Diner, \& Toktas, 2013).

O estudo de Jonker, Jansen, Christians e Wolf (2014) buscou mapear a perspectiva de mulheres e profissionais sobre o atendimento em uma casa-abrigo na Holanda. As mulheres que já estiveram abrigadas mencionaram que o abrigo deve ser um ambiente transparente e seguro, em que os profissionais devem reforçar a individualidade e independência das mulheres. Essas participantes também pontuaram que no abrigo deveria ser oferecida assistência relacionada às atividades de trabalho e aprendizagem, auxílio para resolver questões financeiras e jurídicas e atendimento psicológico disponível após a saída do local. Os profissionais, por sua vez, reforçaram a necessidade de haver segurança e cuidados adequados para as crianças, bem como a implementação de um atendimento personalizado e respeitoso visando ao fim da violência.

Quanto aos profissionais, no que se refere aos estudos em que eles são protagonistas, apenas um artigo procurou saber como é para eles trabalharem em uma casa-abrigo e com a temática da violência contra a mulher e nenhum outro pesquisou aspectos relacionados diretamente à prática ou à intervenção. Os profissionais diariamente atendem situações de violência e este é um tema que pode gerar mobilização por, em alguns momentos, ultrapassar a condição profissional para a pessoal, podendo impactar na sua prática. Por essa razão, a importância da atenção e cuidado também com esses profissionais pode se basear na repercussão da sua prática pois, conforme apontado por Rocha (2007), as mulheres abrigadas avaliam positivamente $o$ atendimento recebido nas casas-abrigos por profissionais de diferentes áreas de formação, os quais as ajudaram na recuperação da sua autoestima e da dignidade. Isto sugere reflexões sobre o necessário preparo desses profissionais para atenderem as mulheres, desde sua formação acadêmica até a prática profissional por meio de educação permanente e supervisão local.

Com relação aos estudos que trataram sobre a saída da casa-abrigo (1.3), a pesquisa de Alsaker, Moen e Kristoffersen (2008) revelou, com base na análise de regressão, que, após um ano da saída do abrigo, as mulheres que sofreram violência física grave apresen- taram uma melhora inferior no que se refere à saúde física e mental, aos aspectos emocionais e às relações sociais, ao comparar com os resultados do questionário aplicado quando estas mulheres estavam na casa-abrigo. Da mesma maneira, as mulheres que sofreram violência psicológica grave tiveram menos melhora na saúde mental e nas relações sociais. O aumento na qualidade de vida pôde ser verificado no grupo de mulheres que deixaram seus parceiros após sua saída do abrigo (Alsaker et al., 2008).

A pesquisa de Ham-Rowbotton, Gordon, Jorvis e Novaco (2005), por sua vez, mostrou que as mulheres tiveram dificuldades financeiras logo após saírem da casa-abrigo, principalmente por não terem renda e/ ou habitação. No momento da entrevista, seis meses após a saída da casa-abrigo, $75 \%$ das mulheres disseram ter um emprego, 59\% relataram estar satisfeitas com sua condição de moradia e $84 \%$ com a capacidade de ser uma boa mãe. Sessenta por cento das mulheres iniciaram um novo relacionamento e $96 \%$ delas relataram não sofrer violência (Ham-Rowbotton et al., 2005). Ainda sobre a satisfação de vida após a saída da casa-abrigo, outro estudo (Ben-Porat, \& Itzhaky, 2008) mostrou que, entre o grupo de mulheres que esteve no abrigo, os aspectos relacionados aos recursos pessoais, à autoestima, bem como à participação e ao empenho nas atividades realizadas no local contribuíram para a sua satisfação de vida.

Esses estudos produzidos com as mulheres após a passagem pela casa-abrigo revelaram melhora na qualidade de vida, porém não deixam claro se essa melhora teve relação com as práticas profissionais desempenhadas no local. O que se observou é que há estudos que se aproximaram da casa-abrigo para recrutar as participantes, mas que seus objetivos de investigação não tinham relação direta com as práticas realizadas no local. Com relação à reinserção social das mulheres, os estudos encontrados apontaram para a dificuldade financeira, de moradia e de trabalho em um curto espaço de tempo após a saída da casa-abrigo. Esse é um dado que desafia pesquisadores a se aproximarem das mulheres e investigarem as repercussões da sua passagem pela casa-abrigo, visando tanto às repercussões das práticas profissionais no conjunto de estratégias de enfrentamento, como também ao monitoramento da efetividade dessas práticas na vida das mulheres, após saírem da casa-abrigo.

Os resultados dos estudos que compõem esta categoria temática revelaram aspectos positivos rela- 
cionados a casa-abrigo, tais como o fato de as mulheres poderem se sentir ouvidas, apoiadas e do local contribuir para o seu empoderamento, no sentido de resgatar sua dignidade e potencialidades, no enfrentamento da violência. Também se observaram aspectos dificultadores, sobretudo no que se refere à segurança das mulheres e às ações e medidas implementadas (ou não) após a saída da casa-abrigo, como habitação, trabalho e geração de renda, tanto do ponto de vista das mulheres ex-abrigadas quanto dos profissionais do local. Outro elemento em questão é a relação das participantes dos estudos com as pessoas da sua rede social após a passagem pela casa-abrigo, que também não se apresentou como foco dos estudos analisados e sinaliza outra lacuna na produção do conhecimento.

\section{Violência contra a mulher e redes sociais}

Esta categoria congrega 19 estudos, do total dos 33 que fazem parte dessa revisão, e apresenta informações sobre seus dados bibliométricos e principais resultados. Quanto aos dados bibliométricos, no que tange ao ano de publicação, 2013 teve quatro artigos, em 2011 e 2015 foram publicados três estudos, em 2006, 2009, 2012 e 2014 foram dois estudos em cada ano e, em 2008, um estudo foi publicado. Os Estados Unidos $(n=7)$ foram o país que mais produziu pesquisas em torno das redes sociais no contexto da violência contra a mulher, seguido pelo Brasil $(n=6)$, Espanha ( $\mathrm{n}=2)$ e Austrália, México, Bangladesh e Trinidad Tobago com um estudo cada. Quanto à natureza da pesquisa, houve predomínio do tipo qualitativo $(n=11)$, seguido por estudos quantitativos $(n=7)$ e apenas uma pesquisa apresentou métodos mistos.

No tocante aos instrumentos e técnicas de coleta de dados foram utilizados: entrevistas semiestruturadas, Mapas de Redes, grupos focais, observação participante, questionários, escalas e inventários. Destaca-se o uso da entrevista semiestruturada em 10 estudos e de questionários em sete. Cabe mencionar, também, que cinco dos 19 estudos utilizaram mais de um instrumento/técnica para a coleta de dados. As mulheres que sofreram violência foram protagonistas em 17 estudos, um foi empreendido com profissionais que atendiam situações de violência e o outro com membros das redes sociais das mulheres.

Com relação aos principais resultados dos estudos, no que se refere às pessoas da rede social (2.1), entre as primeiras que são procuradas pelas mulheres em situação de violência, estão os(as) amigos(as) e membros da família nuclear (mãe, pai, irmã e irmão). Após procurarem estas pessoas em busca de ajuda, sendo efetiva ou não, em segundo plano as mulheres mencionaram procurar ajuda médica e religiosa, a polícia, curandeiras, benzedeiras, serviços de saúde e judiciais (Bruschi, Paula, \& Bordin, 2006; Hadeed \& El-Bassel, 2006; Lettiere \& Nakano, 2011; Postmus, Severson, Berry, \& Yoo, 2009; Sabina \& Tindale, 2008; Sayem, Begum, \& Moneesha, 2015; Trotter \& Allen, 2009).

Com relação às funções desempenhadas pelas redes (2.2), a família forneceu apoio emocional e ajuda material (Alencar-Rodriguez, \& Cantera, 2014; Krenkel, Moré, \& Motta, 2015; Reina, Maldonado, \& Lohman, 2013). Os mesmos estudos revelaram que amigos, familiares, pessoas da igreja e profissionais vinculados à assistência social foram mencionados como pessoas que forneceram ajuda material e conselhos às mulheres, sobretudo no que se referia ao incentivo para a denúncia e a saída da relação de violência. Por outro lado, na pesquisa de Hadeed e El-Bassel (2006), os conselhos oferecidos pelos familiares não foram bem vistos pelas participantes do estudo, que mencionaram só quererem ser ouvidas e terem seus sentimentos compreendidos, quando o que ocorria, na realidade, é que os familiares acabavam por desvalorizar seus sentimentos, diminuir a gravidade da situação e/ou culpabilizar as mulheres pela situação de violência.

As relações de amizade, por sua vez, eram compostas por um número menor de pessoas se comparado com a família (cinco e 12, respectivamente), mas o apoio oferecido às mulheres foi visto como mais significativo e efetivo, fazendo-as sentirem-se compreendidas por essas pessoas (Hadeed, \& El-Bassel, 2006). Sobre as relações de amizade, Sanicola (2008) afirma que a competência do amigo refere-se às questões afetivas, no sentido de compartilhar as alegrias e dores do outro, guardar segredo, ser leal e até tomar distância quando julgar necessário. $\mathrm{O}$ amigo tem a capacidade de ajudar nas questões relacionais/afetivas, ainda que exista a distância física.

No estudo de Katerndahl, Burge, Ferrer, Becho e Wood (2013), em termos numéricos, as redes de mulheres em situação de violência contatadas nosúltimos três meses eram menores ( 47 pessoas) quando comparadas com as redes das mulheres que não sofriam violência (61 pessoas). As pessoas com quem essas mulheres falaram sobre assuntos importantes corresponderam à média de 2,36, enquanto que o número de pessoas 
mencionadas por mulheres que não sofriam violência era de 3,86. Ao se tomar por base o que afirma Sluzki (2003) sobre o tamanho das redes, aquelas compostas por oito pessoas são consideradas redes de tamanho médio. A efetividade a que o autor se refere, é, por um lado, o fato de as redes estarem sobrecarregadas pelo seu número reduzido e, por outro, supor que alguém esteja cuidando do problema, sendo essas redes numerosas, porém inefetivas.

Nessa perspectiva, ainda sobre as funções desempenhadas pelas pessoas das redes (2.2), as participantes do estudo de Taket, O'Doherty, Valpied e Hegarty (2014) relataram que família e amigos ofereceram apoio emocional, ajuda material, de serviços e companhia social. Mencionaram como inestimável o apoio recebido de familiares e amigos, desde que houvesse empatia, compreensão e respeito, sendo que para elas o mais importante era ser escutada, sem que as pessoas as julgassem. Nessa linha de investigação, a pesquisa de Trotter e Allen (2009) revelou que ao mesmo tempo em que família e os amigos ofereceram apoio emocional, eles minimizaram os sentimentos das mulheres ou se afastaram delas ao saber da situação de violência.

A pesquisa de Latta e Goodman (2011), por sua vez, foi elaborada com base em outra perspectiva, na qual foram realizadas entrevistas com as pessoas da rede social das mulheres em situação de violência. Os participantes mencionaram duas condições para tomarem consciência da presença da violência na vida de suas amigas/familiares: a relação de proximidade afetiva e física/geográfica e a sua própria disponibilidade em reconhecer e admitir a existência da violência. Quando os membros da rede estavam distantes da mulher em situação de violência, não notavam mudanças no seu comportamento que pudessem sinalizar o problema.

Ao analisar os estudos que mencionam a maneira como as pessoas da rede social auxiliaram as mulheres em situação de violência, observou-se que, em sua maioria, estas apresentam as funções como consequência das relações estabelecidas, ou seja, como um produto dessa relação. Nesse sentido, não se evidencia uma análise mais acurada da qualidade e história do vínculo que deu origem às funções.

Quando o acesso às pessoas da rede é dificultoso em decorrência da situação de violência, o isolamento social (2.3) torna-se uma condição vivenciada por algumas mulheres. As pesquisas de Dutra, Prates,
Nakamura e Villela (2013), Krenkel et al. (2015) eVieira, Souza, Tocantins e Pina-Roche (2015) revelaram que o isolamento e o afastamento de pessoas com as quais o parceiro não quer que a mulher se relacionasse ocorrem principalmente por medo das ameaças de morte, de novos episódios de violência, do julgamento das pessoas da rede social e/ ou por vergonha de viver em uma relação violenta. Indo ao encontro dessa informação, os resultados do estudo de Estrada Pineda e Rodríguez Díaz (2011) mostraram que, das 204 mulheres participantes, $65,7 \%$ não denunciaram a situação violência, atitude essa justificada pelas mulheres pelo medo de represálias do autor da violência, sobretudo pelo medo de morrer.

O isolamento social (2.3) também esteve presente na vida de mulheres imigrantes que, afastadas geograficamente de sua rede familiar, buscavam ajuda nos serviços sociais e legais do país em que viviam (Alencar-Rodriguez, \& Cantera, 2014). Os estudos de Amoso, Amoso, Mazkiaran e Irazu (2012) e Reina et al. (2013) mostraram que a rede social das mulheres imigrantes normalmente é menor do que a rede das mulheres nativas e ficam ainda menores por conta do isolamento social exercido pelo autor da violência. Os estudos mencionados também revelaram que, quando a rede social das mulheres imigrantes era grande, não havia apoio da rede para que elas deixassem a relação violenta.

No contexto da violência contra a mulher, especificamente, é característico o afastamento das redes, sejam elas familiares, sejam extrafamiliares, das quais se mantém uma distância tanto emocional quanto geográfica - por medo, vergonha ou culpa - sustentando-se em um sistema fechado, com fronteiras enrijecidas. Esse aspecto favorece a diminuição da regulação social, uma vez que essas fronteiras ficam impedidas de serem ultrapassadas (Sluzki, 2003), o que pode contribuir para a sustentação da condição de vulnerabilidade e dependência da mulher em relação ao companheiro. Assim, considera-se a ausência de redes como um fator dificultador para a saída da situação de violência, contribuindo para a manutenção do problema e alimentando o seu ciclo.

Na tentativa de romper o ciclo da violência, estudos revelam que as mulheres buscaram ajuda com profissionais da rede de suporte social (2.4), tais como em delegacias e centros de referência em assistência social, procurados, principalmente, quando havia risco de morte (Labronici, 2012). No estudo de Brus- 
chi, Paula e Bordin (2006), entre as instituições procuradas estão a polícia/delegacia $(36,8 \%)$, as organizações de proteção à mulher/abrigos $(10,5 \%)$, os centros de saúde (5,3\%) e os ambulatórios de saúde mental (5,3\%). Doze das 17 participantes do estudo de Hadeed e El-Bassel (2006) buscaram ajuda com psicólogos, psiquiatras, médicos, assistentes sociais, organizações não governamentais (ONGs) e relataram que puderam se sentir ouvidas, o que as ajudou no enfrentamento da situação de violência.

A pesquisa de Kamimura, Parekh e Olson (2013) mostrou que o apoio emocional oferecido pelos serviços assistenciais foi importante para a saúde e qualidade de vida das mulheres. As participantes mencionaram melhora na saúde física, mental e bucal, além do nível mais baixo de aflição e depressão, quando comparadas às participantes que relataram terem recebido pouco apoio emocional. Ainda sobre os serviços que compõem a rede de suporte social (2.4), as mulheres participantes do estudo de Reina et al. (2013) disseram ter recebido informações sobre os serviços que estão à disposição para auxiliá-las na busca por ajuda para o enfrentamento do problema da violência, tais como delegacias, centros de referência e casas-abrigo.

Por outro lado, as participantes do estudo de Vieira et al. (2015), ao procurarem pelas redes formais de atendimento às mulheres em situação de violência, não as reconheceram como efetivas no atendimento a suas demandas sociais e de saúde no enfrentamento da violência. Na pesquisa de Sayem et al. (2015), as redes formais ofereceram tanto conselhos para melhorar o relacionamento das mulheres com seus companheiros, quanto, em casos considerados mais graves, procurar uma casa-abrigo para mulheres em situação de violência.

No que diz respeito às redes sociais, estas foram procuradas pelas mulheres em busca de ajuda para o enfrentamento da violência. Desse pedido de ajuda, destacam-se dois pontos: o primeiro sobre a influência positiva das pessoas das redes sociais que auxiliaram as mulheres nessa situação; o segundo refere-se ao não atendimento das expectativas das mulheres ao buscarem pelas pessoas, pois essas últimas emitiram julgamento, minimizaram os sentimentos das mulheres e/ou as incentivaram a permanecer na relação.

Os dados presentes nessa revisão também mostraram que tanto os familiares quanto os amigos nem sempre estão preparados para lidar com as situações de violência e que suas reações podem afetar diretamente as ações das mulheres diante do problema. De acordo com Sluzki (2003), a reação das pessoas procuradas pela mulher em busca de ajuda poderá influenciar a ação ou o isolamento da mulher diante do problema da violência. $\mathrm{O}$ autor afirma ainda que os comentários tecidos pelas pessoas da rede social poderão, ou não, contribuir para impulsionar o indivíduo a cuidar de si, tomar decisões para o enfrentamento das situações de crise, além de possibilitar o fortalecimento da pessoa, em nível social e psicológico.

Conforme apontam Santos e Moré (2011) e concordando com o que evidenciam algumas pesquisas presentes nessa revisão (Dutra et al., 2013; Krenkel et al., 2015; Vieira et al., 2015), há mulheres em situação de violência que não falam sobre seu problema aos familiares, acreditando que os poupariam de lidarem com essa questão dentro da família e/ou evitariam expor sua situação a outrem por vergonha. Nessa perspectiva, quanto mais solitárias as mulheres se encontram, mais dependentes do autor da violência ficam dificultando, assim, $o$ acesso às redes sociais para o enfrentamento do problema da violência (Santos, \& Moré, 2011). Diante das repercussões da relação com as redes sociais no desenvolvimento do indivíduo, é importante que se dê atenção aos significados atribuídos às pessoas das redes, às funções que desempenham e ao grau de compromisso relacional existente, visto que, como aponta Sluzki (2003), as redes podem tanto auxiliar quanto impedir a promoção de mudança.

\section{Considerações finais}

O presente artigo buscou caracterizar a produção científica de artigos empíricos sobre casas-abrigo e redes sociais no contexto da violência contra a mulher. Nesse sentido, a análise e caracterização dos estudos permitiram identificar uma produção escassa sobre a relação entre casas-abrigo e mulheres em situação de violência, tanto no contexto internacional, quanto no cenário brasileiro. Observa-se, também, que esta produção se apresenta sem um nível de crescimento, considerando que a existência de casas-abrigo ocorre desde a década de 1970. Quanto aos estudos sobre a interrelação entre redes sociais e violência contra a mulher, a partir de 2011 as publicações nacionais e internacionais sinalizaram expansão, o que evidencia o reconhecimento do tema e sua importância como um recurso em potencial para o enfrentamento da violência contra a mulher. 
Com base nos resultados apresentados foi possível constatar que a casa-abrigo é um espaço onde as mulheres se sentem protegidas diante da situação extrema de violência que vivenciaram, além de ser um local que oferece apoio emocional e ajuda na busca por trabalho e geração de renda, em alguns casos. Conforme exposto, os estudos evidenciaram que a casa-abrigo, dentro de suas condições, é um local que atua no empoderamento das mulheres e desenvolvimento da sua autonomia, ainda que as especificidades das práticas desses locais não tenham sido amplamente exploradas pela literatura.

Os estudos apresentados também mostraram a importância das redes sociais no enfrentamento da violência e sua influência nesse contexto. Dentre as características das pesquisas, destaca-se que, na maioria dos casos, os membros das redes sociais são procurados pelas mulheres antes das organizações e instituições formais e que a forma de ajuda oferecida pela rede auxilia nas decisões e ações frente à situação de violência. Adicional a isso, com base nos resultados desse estudo, ficou evidente a condição de isolamento social pela qual passam muitas mulheres, seja por medo ou vergonha, o que contribui para a manutenção do ciclo da violência. Assim, o conjunto de resultados apresentado nesse estudo avança em termos de contribuição na produção do conhecimento (teórica e empírica), na medida em que mostra a influência das casas-abrigo e dos membros da rede social significativa no processo de enfrentamento da violência contra a mulher.

A busca pelos artigos que compõem o corpus desse estudo ocorreu no Portal da Capes, o qual congrega um grande número de bases de dados de diferentes áreas do conhecimento. Ainda assim, esta revisão de literatura apresenta algumas limitações. Dentre elas, pode-se mencionar que foi encontrado um número reduzido de estudos empíricos sobre os temas pesquisados. Outra limitação se refere ao recorte do tempo de busca pelos artigos, 11 anos. Assim, sugere-se que novas revisões abranjam um período de tempo maior do que o estabelecido neste estudo, uma vez que se poderá melhor evidenciar o estado da arte sobre o tema.

O desenvolvimento de novos estudos empíricos poderia aprofundar as potencialidades tanto das práticas profissionais realizadas em casas-abrigo e acompanhamento das mulheres ao saírem do local, quanto das redes sociais, em termos de análise das funções e qualidade dos vínculos afetivos, uma vez que podem servir como elementos estratégicos no aprimoramento das políticas públicas para o enfrentamento da violência contra a mulher. Compreender a história e a qualidade do vínculo estabelecido entre as mulheres e as pessoas da sua rede social auxilia a melhor entender as peculiaridades e/ou as singularidades da violência, como um fenômeno relacional.

\section{Referências}

Alencar-Rodriguez, R., \& Cantera, L. M. S (2014). Cómo mujeres inmigrantes enfrentan la violencia em la relación de pareja? Estudos de Psicologia (Natal), 19(1): 4-12. https://doi.org/10.1590/S1413-294X2014000100002

Alsaker, K., Moen, B. E., \& Kristoffersen, K. (2008). Health-related quality of life among abuse women one year after leaving a violent partner. Social Indicators Research, 86, 497-509. https://doi.org/10.1007/s11205-007-9182-7

Arnoso M., Arnoso, A. Mazkiaran, M., \& Irazu, A. (2012). Mujer inmigrante y violencia de gênero: factores de vulnerabilidad y protección social. Migraciones, (32), 169-200.

Ben-Porat, A., \&Itzhaky,H. (2008). Factors that influencelifesatisfaction amongbattered womenin shelters: those who say versus those who leave. Journal of FamilyViolence, 23(7), 597-604. https://doi.org/10.1007/s10896-008-9182-7

Brasil. Secretaria de Políticas para as Mulheres - SPM. (2011). Diretrizes Nacionais para o abrigamento de mulheres em situação de risco e violência. Brasília, DF: o Autor.

Bruschi, A., Paula, C. S., \& Bordin, I. A. S. (2006). Prevalência e procura de ajuda na violência conjugal física ao longo da vida. Revista de Saúde Pública, 40(2), 256-64. https://doi.org/10.1590/S0034-89102006000200011

Constantino, R. C., Kim, Y., \& Crane, P. A. (2005). Effects a social support intervention on health outcomes in residents of a domestic violence shelter: a pilot study. Issues Mental Health Nursing, 26(6), 575-590. https://doi.org/10.1080/01612840590959416

Critelli, F. M. (2012). Voices of resistence: Seekin shelter services in Pakistan. Violence Against Women, 18(4), 437-458. https://doi.org/ 10.1177/1077801212452104 
Critelli, F. M., \& Wilett, J. (2010). Creating a safe having in Pakistan. Internacional Social Work, 53(3), 407-422. https://doi.org/10.1177/0020872809359868

Diner, C., \& Toktas, S. (2013). Women's shelter in Turkey: a qualitative study on shortcomings of policy making and implementation. Violence Against Women, 19(3), 338-355. https://doi.org/10.1177/ 1077801213486258

Dutra, M.L., Prates, P. L., Nakamura, E., \&Villela,W.V. (2013). A configuração da rede social demulheres em situação de violênciadoméstica. Ciência\&SaúdeColetiva, 18(5),1293-1304.https://doi.org10.1590/S1413-81232013000500014

Estrada Pineda, C., \& Rodríguez Díaz, F. J. (2011). Violencia y temor por la vida en mujeres jaliscienses violentadas por su pareja íntima. Revista Cubana de Salud Pública, 37(4), 462-471.

Few, A. L. (2005). The voices of black and white rural battered women in domestic violence shelters. Family Relations, 54(4), 488-500.

Galano, M. M., Hunter, E. C., Howell, K. H., Miller, L. E., \& Graham-Bermann, S. A. (2013). Predicting shelter residence in women experiencing recent intimate partner violence. Violence Against Women, 19(4), 518-535. https://doi.org/10.1177/1077801213487056

Glenn,C., \&Goodman,L. (2015).Livingwithand within therulesofdomestic violenceshelters: aqualitativeexploration of residents' experiences. Violence AgainstWomen, 21(12), 1481-1506. https:// doi.org/10.1177/1077801215596242

Gonçalves, T. R., Pawlowski, J., Bandeira, D. R., \& Piccinini, C. A. (2011). Avaliação de apoio social em estudos brasileiros: Aspectos conceituais e instrumentos. Ciência \& Saúde Coletiva, 16(3), 1755-1769. https://doi.org/10.1590/S1413-81232011000300012

Hadeed, L. F., \& El-Bassel, N. (2006). Social support among Afro-Trinidadian women experiencing intimate partner violence. Violence Against Women, 12(8), 740-760. https://doi.org/10.1177/1077801206291562

Ham-Rowbotton, K. A., Gordon, E. E., Jarvis, K. L, \& Novaco, R. W. (2005). Life constraints and psychological well-being of domestic violence shelter graduates. Journal of Family Violence, 20(2), 109-121. https://doi.org/10.1007/s10896-005-3174-7

Jonker, I. E., Jansen, C. C. J. M., Christians, M. G. M., \& Wolf, J. R. L. M. (2014). Appropriate care for shelter-based abused women: concept mapping with Dutch clients and professionals. Violence Against Women, 20(4), 465-480. https://doi.org/10.1177/1077801214528580

Kamimura, A., Parekh, A., \& Olson, L. M. (2013). Health indicators, social support, and intimate partner violence among women utilizing services at a community organization. Women's Health Issues, 23(3), 179-185. https://doi.org/10.1016/j.whi.2013.02.003

Katerndahl, D., Burge, S., Ferrer, R., Becho, J., \& Wood, R. (2013). Differences in social network structure and support among women in violent relationships. Journal of interpersonal violence, 28(9), 1948-1964. https://doi.org/10.1177/0886260512469103

Krenkel, S., Moré, C. L. O. O., \& Motta, C. C. L. (2015). The significant social networks of women who have resided in shelters. Paidéia (Ribeirão Preto), 25(60), 125-133. https://doi.org/10.1590/1982-43272560201515

Labronici, L. M. (2012). Processo de resiliência nas mulheres vítimas de violência doméstica: um olhar fenomenológico. Texto \& Contexto Enfermagem, 21(3),625-632. https:// doi.org/10.1590/S0104-07072012000300018

Latta, R. E., \& Goodman, L. A. (2011). Intervening in partner violence against women: a grounded theory exploration of informal network members' experiences. The Counseling Psychologist, 39(7), 973-1023. https://doi.org/10.1177/0011000011398504

Lettiere, A., \& Nakano, A. M. S. (2011). Violência doméstica: as possibilidades e oslimites de enfrentamento. Revista Latino-Americana de Enfermagem, 19(6), 1421-1428. https:// doi.org/10.1590/S0104-11692011000600020

Magalhães, M. J., Morais, C., \& Castro, Y. R. (2011). Organização e funcionamento duma casa de abrigo de solidariedade social. Psicologia \& Sociedade, 23(3), 598-607. https://doi.org/10.1590/S0102-71822011000300018

Olabuénaga, J. I. R. (2009). Metodología de la investigación cualitativa. Bilbao: Universidad de Deusto.

Ornelas, J. (2008). Psicologia comunitária. Lisboa: Fim de século.

Ossó, A. B. (2014). Escuchar, observar y comprender: recuperando la narrativa en las ciencias de la salud. Catalúnia: Taller Gráfic. 
Postmus, J. L., Severson, M., Berry, M., \& Yoo, J. A. (2009). Women’s experiences of violence and seeking help. Violence Against Women, 15(7), 852-868. https:// doi.org/10.1177/1077801209334445

Reina, A. S., Maldonado, M. M., \& Lohman, B. J. (2013). Undocumented Latina networks ad responses to domestic violence in a new immigrant gateway: toward a place-specific analysis. Violence Against Women, 19(12), 1472-1497. https://doi.org/10.1177/1077801213517513

Rocha, L. M. L. N. (2007). Casas-abrigo no enfrentamento da violência de gênero. São Paulo, SP: Veras.

Rosa, T. E. C., Benício, M. H. D., Alves, M. C. G. P., \& Lebrão, M. L. (2007). Aspectos estruturais e funcionais do apoio social de idosos no Município de São Paulo. Caderno de Saúde Pública, 23(12), 2982-2992. https://doi.org/10.1590/S0102-311X2007001200019

Sabina, C., \& Tindale, R. S. (2008). Abuse characteristics and coping resources as predictors of problem-focused coping strategies among battered women. Violence Against Women, 14(4), 437-456. https://doi.org/10.1177/1077801208314831

Sanicola, L. (2008). As dinâmicas de rede e o trabalho social. São Paulo, SP: Veras Editora.

Santos, A. C. W., \& Moré, C. L. O. O. (2011). Impacto da violência no sistema familiar de mulheres vítimas de agressão. Psicologia, Ciência e Profissão, 31(2), 220-235. https://doi.org/10.1590/S1414-98932011000200003

Sayem, A. M., Begum, H. A., \& Moneesha, S. S. (2015). Women's attitudes towards formal an informal support-seeking coping strategies against intimate partner violence. International Social Work, 58(2), 270-286. https://doi.org/10.1177/0020872813482957

Sluzki, C. E. (2003). A rede social na prática sistêmica: Alternativas terapêuticas. São Paulo, SP: Casa do Psicólogo.

Taket, A., O'Doherty, L., Valpied, J., \& Hegarty, K. (2014). What do Australian women experiencing intimate partner abuse want from family and friends? Qualitative Health Research, 24(7), 983-996. https://doi.org/10.1177/1049732314540054

Trotter, J. L., \& Allen, N. E. (2009). The good, the bad, and the ugly: domestic violence survivors' experiences with their informal social networks. American Journal of Community Psychology, 43(3-4), 221-231. https://doi.org/10.1007/s10464-009-9232-1

Tutty, L. M. (2015). Addressing the safety and trauma issues of abused women: A Cross-Canada study of YWCA shelters. Journal of International Women's Studies, 16(3), 101-116.

United Nations. (1993). Declaration on the elimination of violence against women. General Assembly Resolution $\mathrm{n}^{\circ}$. A/RES/48/104, Geneve: United Nations.

Vieira, L. B., Souza, I. E. O., Tocantins, F. R., \& Pina-Roche, F. (2015). Apoio à mulher que denuncia o vivido de violência a partir de sua rede social. Rev. Latino-Am. Enfermagem, 23(5), 865-873.

World Health Organization - WHO. (2014). Violence against women. Intimate partner and sexual violence against women. Recuperado em 13 de maio de 2015, de http://www.who.int/mediacentre/factsheets/fs239/en/

Wright, R., Kiguwa, P., \& Potter, C. (2007). The significance of sheltering in the lives of four women affect by abusive relationship. South African Journal of Psychology, 37(3), 616-637.

\section{Scheila Krenkel}

Mestrado em Psicologia pela Universidade Federal de Santa Catarina, Brasil (2014); Doutoranda do Programa de Pós-Graduação em Psicologia da Universidade Federal de Santa Catarina. E-mail: scheilakrenkel@gmail.com

\section{Carmen Leontina Ojeda Ocampo Moré}

Doutorado em Psicologia (Psicologia Clínica) pela Pontifícia Universidade Católica de São Paulo, Brasil (2000); Professora Titular da Universidade Federal de Santa Catarina. E-mail: carmen.more@ufsc.br

Endereço para envio de correspondência:

Scheila Krenkel. Universidade Federal de Santa Catarina, Campus Universitário Reitor João David Ferreira Lima. Centro de Filosofia e Ciências Humanas, Bloco C, Trindade. CEP 88040-500. Florianópolis - SC, Brasil. 
Recebido 18/01/2016

Reformulação 10/05/2017

Aprovado 02/08/2017

Received 01/18/2016

Reformulated 05/10/2017

Approved 08/02/2017

Recebido 18/01/2016

Reformulado 10/05/2017

Aceptado 02/08/2017

Como citar: Krenkel, S., \& Moré, C. L. O. O. (2017). Violência contra a mulher, casas-abrigo e redes sociais: revisão sistemática daliteratura. Psicologia:CiênciaeProfissão, 37(3), 770-783.https://doi.org/10.1590/1982-3703000192016

How to cite: Krenkel, S., \& Moré, C. L. O. O. (2017). Violence against women, shelters and social networks: systematic review of the literature. Psicologia: Ciência e Profissão, 37(3), 770-783. https://doi.org/10.1590/1982-3703000192016

Cómo citar: Krenkel, S., \& Moré, C. L. O. O. (2017). Violencia contra la mujer, casas de acogida y redes sociales: revisión sistemática de la literatura. Psicologia: Ciência e Profissão, 37(3), 770-783. https://doi.org/10.1590/1982-3703000192016 